\title{
Dynamic Vibration Absorber with Negative Stiffness for Rotor System
}

\author{
Hongliang Yao, Zidong Chen, and Bangchun Wen \\ School of Mechanical Engineering and Automation, Northeastern University, Shenyang 110819, China \\ Correspondence should be addressed to Hongliang Yao; hlyao@mail.neu.edu.cn
}

Received 11 July 2016; Revised 14 October 2016; Accepted 23 October 2016

Academic Editor: Mahmoud Bayat

Copyright ( 2016 Hongliang Yao et al. This is an open access article distributed under the Creative Commons Attribution License, which permits unrestricted use, distribution, and reproduction in any medium, provided the original work is properly cited.

\begin{abstract}
To suppress the vibration of a rotor system, a vibration absorber combining negative stiffness with positive stiffness together is proposed in this paper. Firstly, the negative stiffness producing mechanism using ring type permanent magnets is presented and the characteristics of the negative stiffness are analyzed. Then, the structure of the absorber is proposed; the principles and nonlinear dynamic characteristics of the absorber-rotor system are studied numerically. Finally, experiments are carried out to verify the numerical conclusions. The results show that the proposed vibration absorber is effective to suppress the vibration of the rotor system, the nonlinearity of the negatives stiffness affects the vibration suppression effect little, and the negative stiffness can broaden the effective vibration control frequency range of the absorber.
\end{abstract}

\section{Introduction}

Vibrations of rotor system are the source of many faults in rotating machinery such as rotor-to-stator rub and shaft crack growth. To maintain the safety operation of the rotating machinery, the excessive vibration of rotor system must be controlled.

Many studies have been carried out about vibration suppression methods of rotor systems, which can be largely divided into three kinds: vibration control by applying external forces, vibration reduction by adjusting parameters, and vibration absorbing by using dynamic vibration absorbers.

The first kind of method is by applying external forces, which are usually produced by active magnetic bearings or active magnetic exciters [1-4]. The advantage of magnetic forces is that they can be acted on the rotating parts contactless, thus changing the structure of the rotor little.

The second kind of method is by adjusting parameters of the rotor system such as stiffness, damping, and eccentricity, which can be carried out by using shape memory alloy metals [5], discontinuous springs [6], and so forth. In all these methods, the damping adjusting methods are more popular and many approaches are used, such as squeeze film dampers [7], eddy current damping [8, 9], piezoceramic induced damping [10], magnetorheological elastomer damping [11-13], and friction controlled damping [14]. Eccentricity adjusting is another kind of popular method and is mainly realized by using an automatic ball balancer $[15,16]$, which can be very efficient when the rotating speed is above the critical speed.

The third kind of method is using a vibration absorber or a nonlinear energy sink, by which the vibration of the rotor system can be "absorbed." For example, the centrifugal pendulum vibration absorbers have long been widely used in torsional vibration suppression [17]. In lateral vibration attenuation, many studies are also carried out; the vibration absorbers are placed on the bearing or foundation $[18,19]$ or inside the rotating parts [20-22]. As the lateral vibrations of rotor system are in both the horizontal and vertical directions, ring type absorbers are widely used for vibration suppression of the rotor system. For example, in [23], a new kind of viscoelastic vibration absorber was designed for the rotating system and the experiment results verified the vibration suppression effect; in [24], a tunable vibration absorber is designed to suppress regenerative chatter in milling process; in [25], a vibration absorber for a washing machine is proposed, which is mounted on the rotating basket of the machine; in [26], a circular shape vibration absorber to 

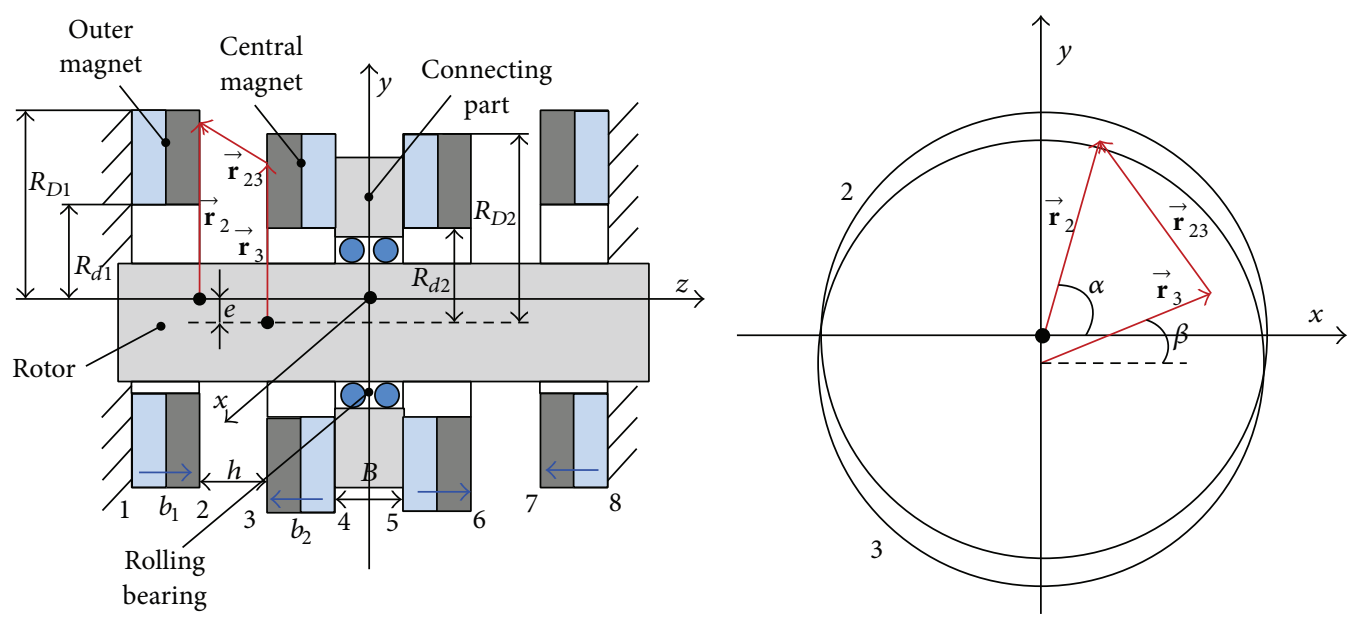

FIGURE 1: Structure of the magnetic spring with negative stiffness.

reduce the vibration caused by the imbalance of an optical disk drive is presented; the vibration absorber is speeddependent and can keep resonance in a specific frequency range.

The vibration absorbers often become inefficient in the low frequency range, because it is difficult to reduce the stiffness of absorber to very low values, as the low stiffness will cause large static deflection. Negative stiffness is a good solution for this problem and has been widely used in vibration isolator design. Permanent magnets are a good way to produce negative stiffness and have been widely used in single-direction vibration suppression, such as vibration isolators [27] or dynamic vibration absorbers [28], but, to the authors' knowledge, no permanent magnet has been used in dynamic vibration absorber design for rotor system.

So, in this paper, a novel vibration absorber with negative stiffness produced by permanent magnet is proposed and its fundamental principles and characteristics are studied, and then experiments are carried out to verify the analytical results.

\section{Negative Stiffness Spring Made Up of Permanent Magnets}

2.1. Structure of the Negative Stiffness Magnetic Spring. The structure is made up of ring type magnets and is shown as Figure 1 . The outer magnets and central magnets are mounted in repulsive interaction, and the two central magnets are connected by a connecting part which contains a rolling bearing.

As the outer magnet and the central magnet are in repulsive interaction, a repulsive force in radial direction will occur; the central magnet will leave the equilibrium position and will not return without external force. So the central magnet acts as a spring with negative stiffness.

2.2. Magnet Force and Stiffness Calculation Using Equivalent Magnetic Charge Method. The magnet force generated between the two parallel ring type magnets can be calculated by using equivalent magnetic charge method $[29,30]$.

The outer diameter, inner diameter, and thickness of the outer magnets are $R_{D 1}, R_{d 1}$, and $b_{1}$, and those of the inner magnets are $R_{D 2}, R_{d 2}$, and $b_{2}$, respectively. The distance between the outer magnet and the central magnet is $h$. The width of the rolling bearing is $B$. According to the equivalent magnetic charge method, the point charge of a point $\left(r_{2}, \alpha\right)$ in plane 2 (as shown in Figure 1) is

$$
q_{2}=B_{r} r_{2} \mathrm{~d} r_{2} \mathrm{~d} \alpha,
$$

where $B_{r}$ is the residual flux density.

The point charge of a point $\left(r_{3}, \beta\right)$ in plane 3 is

$$
q_{3}=B_{r} r_{3} \mathrm{~d} r_{3} \mathrm{~d} \beta .
$$

The interaction force between the two points is

$$
\mathrm{d} \overrightarrow{\mathbf{F}}_{23}=\frac{B_{r}^{2}}{4 \pi \mu_{0}} \frac{r_{2} r_{3} \mathrm{~d} r_{2} \mathrm{~d} \alpha \mathrm{d} r_{3} \mathrm{~d} \beta}{r_{23}^{2}} \overrightarrow{\mathbf{r}}_{23},
$$

where $\mu_{0}$ is the relative permeability of the permanent magnets.

When the central magnets leave the equilibrium point for distance $e$, the interaction force between planes 2 and 3 is

$$
F_{23}=\frac{B_{r}^{2}}{4 \pi \mu_{0}} \int_{0}^{2 \pi} \int_{0}^{2 \pi} \int_{R_{d 1}}^{R_{D 1}} \int_{R_{d 2}}^{R_{D 2}} \frac{r_{2} r_{3}\left(r_{3} \cos \beta-r_{1} \cos \alpha-e\right)}{\left[\left(r_{3} \cos \beta-r_{1} \cos \alpha-e\right)^{2}+\left(r_{3} \sin \beta-r_{1} \sin \alpha\right)^{2}+h^{2}\right]^{3 / 2}} \mathrm{~d} r_{2} \mathrm{~d} r_{3} \mathrm{~d} \alpha \mathrm{d} \beta
$$


TABLE 1: Parameters for numerical simulation of magnetic force and stiffness.

\begin{tabular}{lc}
\hline Parameter & Value \\
\hline$R_{D 1}$ & $50 \mathrm{~mm}$ \\
$R_{d 1}$ & $25 \mathrm{~mm}$ \\
$b_{1}$ & $6 \mathrm{~mm}$ \\
$R_{D 2}$ & $50 \mathrm{~mm}$ \\
$R_{d 2}$ & $25 \mathrm{~mm}$ \\
$b_{2}$ & $6 \mathrm{~mm}$ \\
$B$ & $15 \mathrm{~mm}$ \\
$\mu_{0}$ & $4 \pi \times 10^{-7} \mathrm{~N} / \mathrm{A}^{2}$ \\
$B_{r}$ & $1.34 \mathrm{~T}$ \\
\hline
\end{tabular}

TABLE 2: Parameters for approximate stiffness.

\begin{tabular}{lccc}
\hline$h(\mathrm{~mm})$ & $k_{m 1}(\mathrm{~N} / \mathrm{mm})$ & $k_{m 2}(\mathrm{~N} / \mathrm{mm})$ & $k_{m 3}(\mathrm{~N} / \mathrm{mm})$ \\
\hline 20 & -1.212 & 0.012 & -0.001 \\
15 & -2.48 & 0.033 & -0.002 \\
10 & -5.898 & 0.112 & -0.008 \\
5 & -17.28 & 0.637 & -0.054 \\
2.5 & -35.88 & 3.238 & -0.434 \\
\hline
\end{tabular}

The interaction force between plane 2 and plane $i$ can be written as

$$
F_{2 i}=(-1)^{i+1} \frac{B_{r}^{2}}{4 \pi \mu_{0}} \int_{0}^{2 \pi} \int_{0}^{2 \pi} \int_{R_{d 1}}^{R_{D 1}} \int_{R_{d 2}}^{R_{D 2}} \frac{r_{2} r_{i}\left(r_{i} \cos \beta-r_{2} \cos \alpha-e\right)}{\left[\left(r_{i} \cos \beta-r_{2} \cos \alpha-e\right)^{2}+\left(r_{i} \sin \beta-r_{2} \sin \alpha\right)^{2}+h_{2 i}^{2}\right]^{3 / 2}} \mathrm{~d} r_{2} \mathrm{~d} r_{i} \mathrm{~d} \alpha \mathrm{d} \beta
$$

$$
(i=3, \ldots, 6) \text {, }
$$

where $h_{23}=h, h_{24}=h+b_{2}, h_{25}=h+b_{2}+B$, and $h_{26}=$ $2 h+b_{2}+B$.
Also, the interaction force between plane 1 and plane $i$ can be written as

$$
F_{1 i}=(-1)^{i} \frac{B_{r}^{2}}{4 \pi \mu_{0}} \int_{0}^{2 \pi} \int_{0}^{2 \pi} \int_{R_{d 1}}^{R_{D 1}} \int_{R_{d 2}}^{R_{D 2}} \frac{r_{1} r_{i}\left(r_{i} \cos \beta-r_{1} \cos \alpha-e\right)}{\left[\left(r_{i} \cos \beta-r_{1} \cos \alpha-e\right)^{2}+\left(r_{i} \sin \beta-r_{1} \sin \alpha\right)^{2}+\left(b_{1}+h_{2 i}\right)^{2}\right]^{3 / 2}} \mathrm{~d} r_{1} \mathrm{~d} r_{i} \mathrm{~d} \alpha \mathrm{d} \beta
$$

$$
(i=3, \ldots, 6) \text {. }
$$

As the structure is symmetrical, the interaction forces between the right outer magnet and the central magnets are equal to those of the left ones. So the total force between the central magnets and the outer magnets is

$$
F_{y}=2 \sum_{i=3}^{6}\left(F_{1 i}+F_{2 i}\right) \text {. }
$$

Equations (4)-(7) can be solved numerically. When the different forces $F_{y}$ with different $e$ are obtained, the radial stiffness of the negative stiffness magnetic spring can be obtained by

$$
k_{m}=\frac{\mathrm{d} F_{y}}{\mathrm{~d} e} .
$$

2.3. Numerical Simulation and Stiffness Analysis. The parameters used for numerical simulation are shown in Table 1.

When the distance between the outer magnet and the central magnet changes from 1 to $5 \mathrm{~mm}$ and the distance from the center of central magnet to the equilibrium point changes from 0 to $1 \mathrm{~mm}$, the magnetic force in the radial direction is obtained and is shown in Figure 2. It can be seen from Figure 2 that the radial force changes violently when the magnet distance $h$ is small.
The negative stiffness can be calculated by (8), and the stiffness of different $h$ is shown in Figure 3. It can be seen from Figure 3 that the nonlinearity is weak when $h$ is large, and the nonlinearity increases with the decrease of $h$ and becomes suddenly evident when $h$ is $2.5 \mathrm{~mm}$.

When polynomial fitting is applied, the relationship between the total stiffness and the radial displacement can be written as

$$
k_{m}=k_{m 1}+k_{m 2} e^{2}+k_{m 3} e^{4} .
$$

The parameters of different magnet distances are shown in Table 2 and the fitting effects are shown in Figure 4. It can be seen from Table 2 and Figure 4 that the polynomial fitting effect is rather good, and $k_{m 2}$ and $k_{m 3}$ are rather small when $h$ is larger.

\section{Dynamic Vibration Absorber with Magnetic Spring}

3.1. Structure of the Dynamic Vibration Absorber. The structure of the absorber is shown in Figure 5(a) and that of the whole test rig is shown in Figure 5(b). The central magnets are fixed on the connecting part. The connecting part is mounted on the rolling bearing. With the rolling bearing, the absorber 


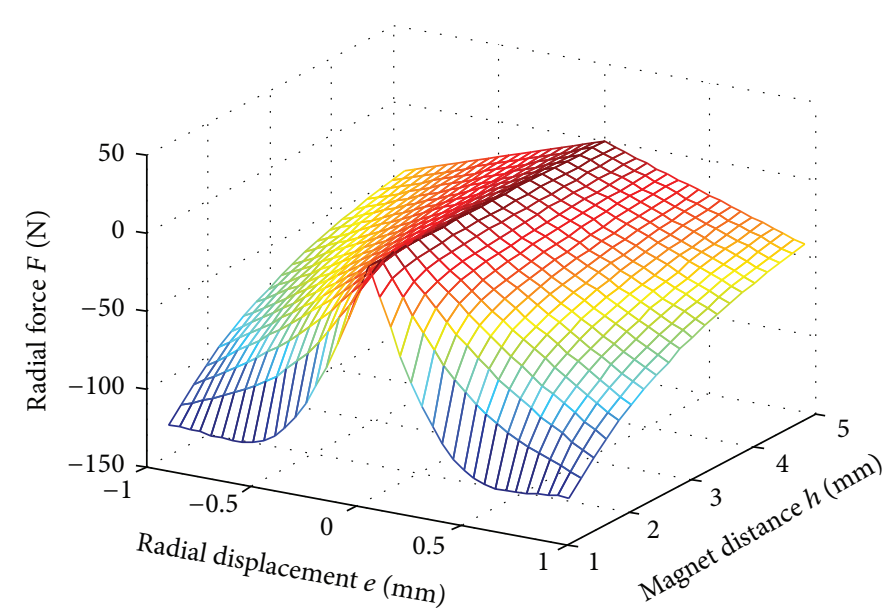

FIgURE 2: Magnetic force of the negative stiffness structure.

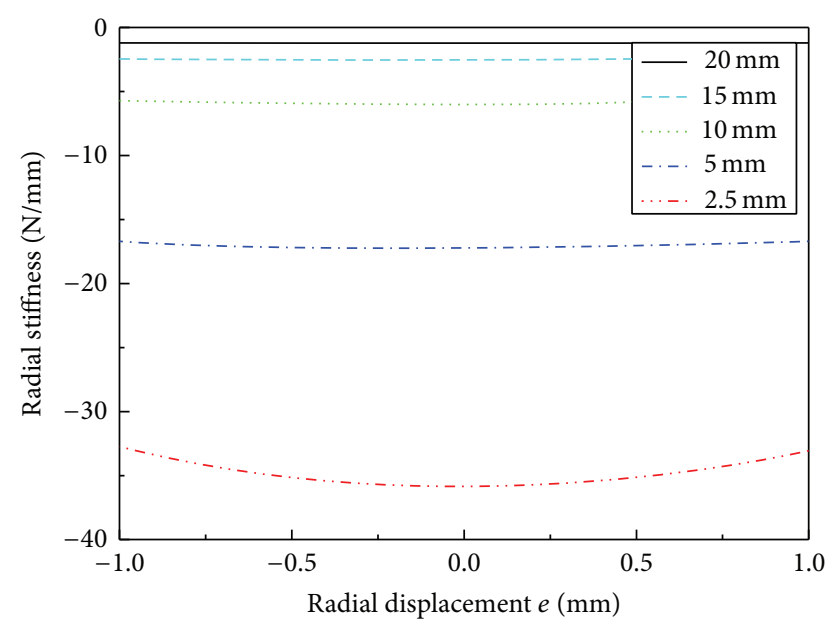

FIgURE 3: Stiffness of the magnetic spring when the distance is from 2.5 to $20 \mathrm{~mm}$.

will not rotate with the shaft together, so the electromagnetic damping between the central magnet and the frame of the absorber can be avoided. The outer magnets are fixed on the aluminum plates, which are connected by beams with circular section. The circular section beams are connected to the supporting frame by linear bearings, which ensure that the beams have single-direction stiffness in the lateral vibration plane: the vertical beam has stiffness in horizontal direction and the horizontal beam has stiffness in vertical direction, as shown in Figure 5(c). The beams act as positive stiffness springs and the magnet structure acts as negative stiffness spring.

The dynamic model of the unbalanced rotor-absorber system is shown in Figure 6, and the dynamic equations of the system are

$$
\begin{gathered}
{\left[\begin{array}{cc}
m_{1} & 0 \\
0 & m_{2}
\end{array}\right]\left\{\begin{array}{l}
\ddot{r}_{1} \\
\ddot{r}_{2}
\end{array}\right\}+\left[\begin{array}{cc}
c_{1}+c_{m} & -c_{m} \\
-c_{m} & c_{m}+c_{3}
\end{array}\right]\left\{\begin{array}{l}
\dot{r}_{1} \\
\dot{r}_{2}
\end{array}\right\}} \\
+\left[\begin{array}{cc}
k_{1}+k_{m 1} & -k_{m 1} \\
-k_{m 1} & k_{m 1}+k_{3}
\end{array}\right]\left\{\begin{array}{l}
r_{1} \\
r_{2}
\end{array}\right\}
\end{gathered}
$$

$$
\begin{aligned}
& +\left\{\begin{array}{c}
k_{m 2}\left(r_{1}-r_{2}\right)^{3}+k_{m 3}\left(r_{1}-r_{2}\right)^{5} \\
-k_{m 2}\left(r_{1}-r_{2}\right)^{3}-k_{m 3}\left(r_{1}-r_{2}\right)^{5}
\end{array}\right\} \\
& =\left\{\begin{array}{c}
m_{e} \delta \omega^{2} e^{i \omega t} \\
0
\end{array}\right\},
\end{aligned}
$$

where $m_{1}, k_{1}$, and $c_{1}$ are the mass, stiffness, and damping of the rotor, respectively. $k_{m}$ and $c_{m}$ are the stiffness and damping of the negative stiffness structure. $m_{2}$ is the mass of the part of the absorber attached to the rotor and $k_{3}$ is the stiffness of the circular beam. $r_{1}$ and $r_{2}$ are the displacement vectors of the rotor and the absorber in the radial direction, respectively. $m_{e}$ and $\delta$ are the eccentric mass and eccentric distance of the disc, respectively. $\omega$ is the rotating speed of the rotor.

3.2. Numerical Simulation of the Dynamic Responses of the Rotor-Absorber System. When the nonlinearity of the negative stiffness is considered, numerical simulation must be applied to study the responses of the rotor-absorber system. The Incremental Harmonic Balance (IHB) method [31] is applied in the following analysis. To trace the unstable 


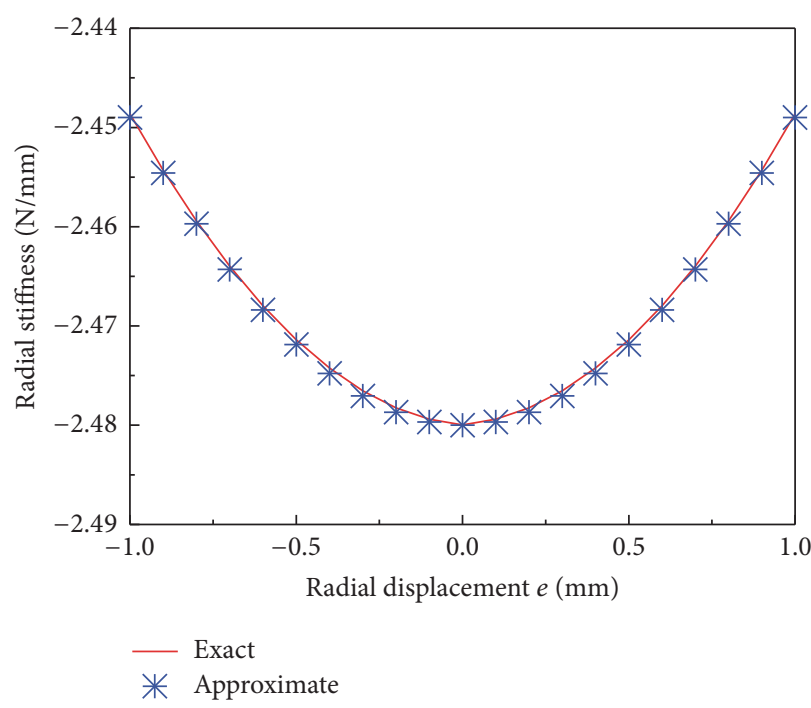

(a) $h=15 \mathrm{~mm}$

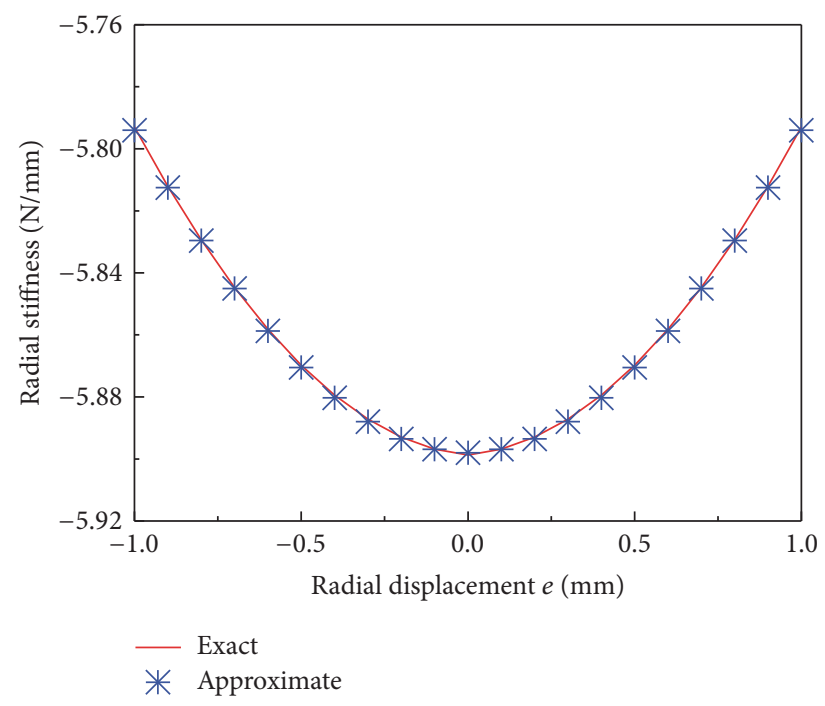

(b) $h=10 \mathrm{~mm}$

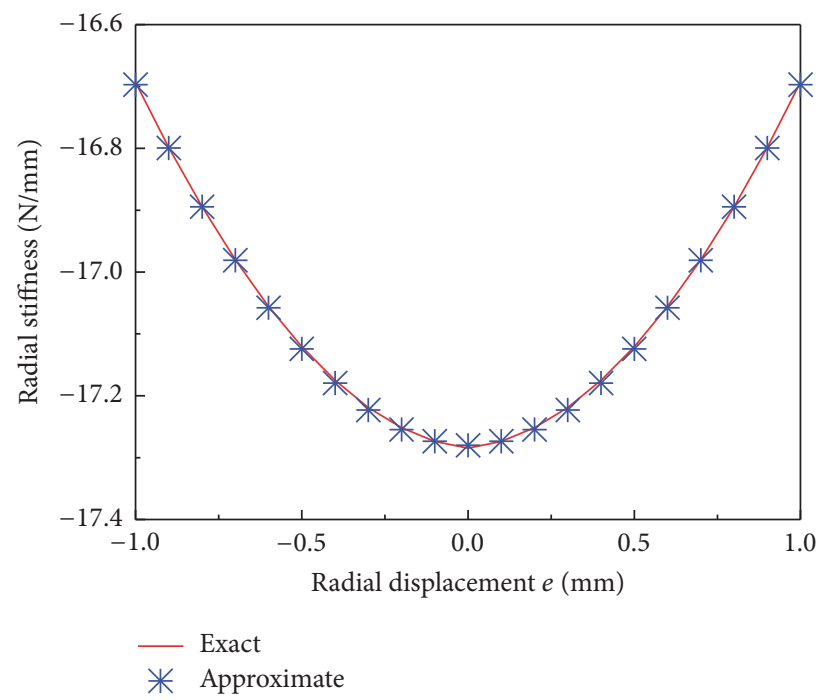

(c) $h=5 \mathrm{~mm}$

Figure 4: Approximate stiffness and exact stiffness comparison when $h$ is $15 \mathrm{~mm}, 10 \mathrm{~mm}$, and $5 \mathrm{~mm}$, respectively.

TABLE 3: Parameters of the rotor-absorber system.

\begin{tabular}{lc}
\hline Parameter & Value \\
\hline$m_{1}$ & $1 \mathrm{~kg}$ \\
$m_{2}$ & $0.7 \mathrm{~kg}$ \\
$k_{1}$ & $9.5 \times 10^{4} \mathrm{~N} / \mathrm{m}$ \\
$c_{m}$ & $0 \mathrm{Nm} / \mathrm{s}$ \\
$c_{1}$ & $10 \mathrm{Nm} / \mathrm{s}$ \\
$c_{3}$ & $6 \mathrm{Nm} / \mathrm{s}$ \\
\hline
\end{tabular}

periodic responses, the arc-length method [32] is combined with the IHB method.

The parameters of the magnets are assumed the same as those in Table 1, and the other parameters of the rotorabsorber system are shown in Table 3.
The stiffness $k_{m}$ is adjusted by the distance $h$ between the outer magnet and the central magnet, and $k_{3}$ is adjusted by the lengths of the circular section beams. For the cantilever beam with length $l$ and diameter $d$, the bending stiffness can be obtained by

$$
k_{3}=\frac{3 \pi E d^{4}}{64 l^{3}}
$$

where $E$ is the elastic modulus of material. When the diameter of the beam is $5 \mathrm{~mm}$ and the length is $67 \mathrm{~mm}, 64 \mathrm{~mm}$, and $61 \mathrm{~mm}$, the stiffness $k_{3}$ is about $6 \times 10^{4} \mathrm{~N} / \mathrm{m}, 7 \times 10^{4} \mathrm{~N} / \mathrm{m}$, and $8 \times 10^{4} \mathrm{~N} / \mathrm{m}$, respectively.

Firstly, the amplitude-frequency response curve of the rotor system without absorber when $\delta$ is $0.015 \mathrm{~mm}$ is shown in Figure 7. It can be seen from Figure 7 that the first-order critical speed is about $50 \mathrm{~Hz}$ and the largest amplitude is about $0.45 \mathrm{~mm}$. 


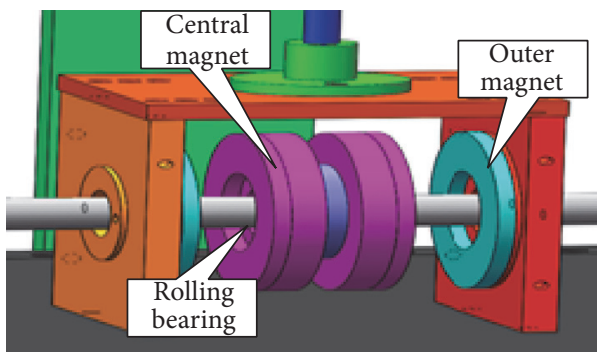

(a) Structure of the absorber

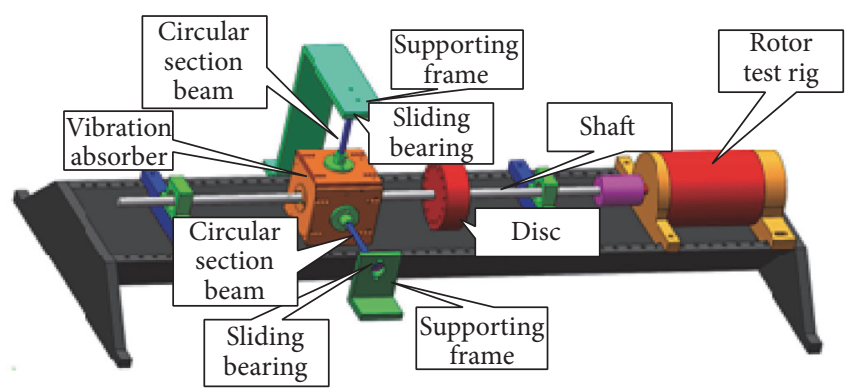

(b) Structure of the whole test rig

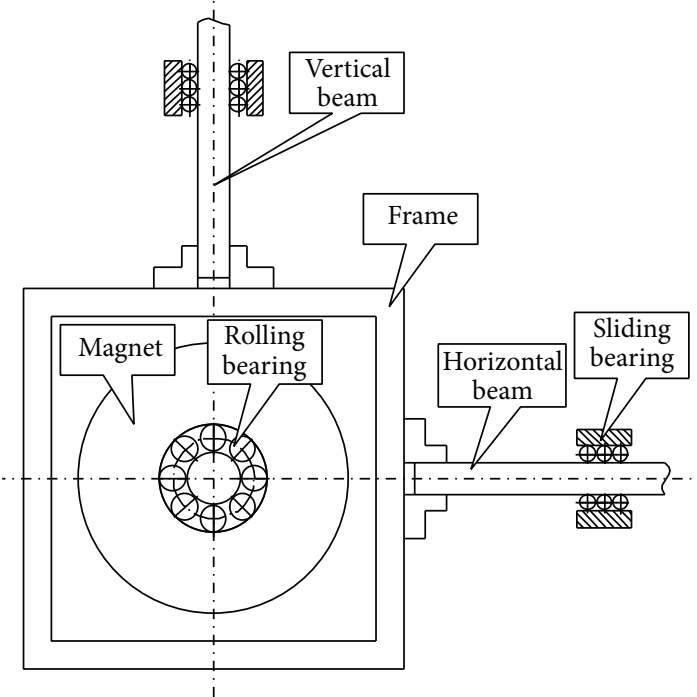

(c) Schematic diagram of the beam installment

FIGURE 5: Structure of the dynamic vibration absorber and the rotor-absorber system.

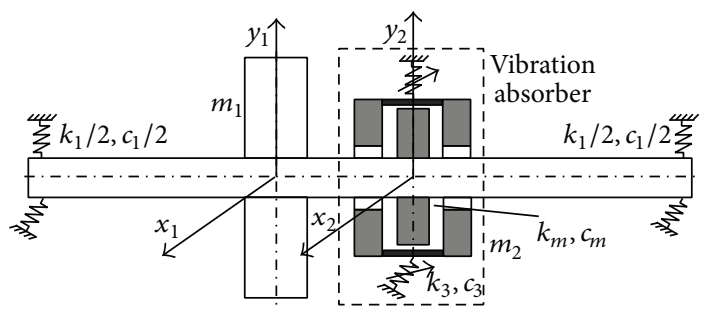

Figure 6: Dynamic model of the rotor-absorber system.

Then the absorber is mounted on the rotor system, and the frequency-amplitude curves of the rotor system and the absorber when $\delta$ is $0.015 \mathrm{~mm}$ are studied. As the nonlinearity of the negative stiffness differs with the distance $h$, here the cases with different distance are studied. Firstly, the responses of the system when $h$ is $10 \mathrm{~mm}$ are calculated. Figures $8(\mathrm{a})$, $8(\mathrm{~b})$, and $8(\mathrm{c})$ are the responses of the rotor and absorber when $k_{3}$ is $6 \times 10^{4} \mathrm{~N} / \mathrm{mm}, 7 \times 10^{4} \mathrm{~N} / \mathrm{mm}$, and $8 \times 10^{4} \mathrm{~N} / \mathrm{mm}$, respectively. Then, the responses of the system when $h$ is $5 \mathrm{~mm}$ are calculated and shown in Figure 9.

Studying Figures 8 and 9, some conclusions can be obtained:

(1) The vibrations of the rotor can be suppressed when the absorber is added. The maximum amplitude of the rotor is much smaller than that of the rotor system without absorber. The antiresonant frequency changes with the change of $k_{3}$, so when the rotating speed of the rotor is determined, we can change $k_{3}$ to keep the small vibration of the rotor.

(2) The vibration suppression effect is better when the distance $h$ is smaller. The residual vibrations in Figure 9 are much smaller than those in Figure 8 and the low vibration regions are much larger.

(3) The nonlinearity affects the suppression effect little, especially near the antiresonant frequency range. Although there exists nonlinearity in the magnetic stiffness, the response curves show little "hard" or "soft" characteristic, because the vibration of the rotor system is small. 


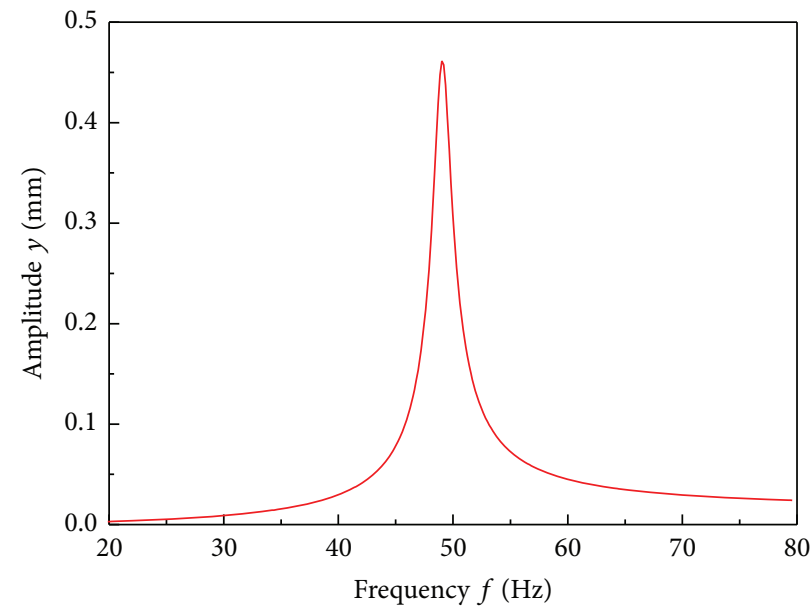

FIGURE 7: Responses of the rotor system.
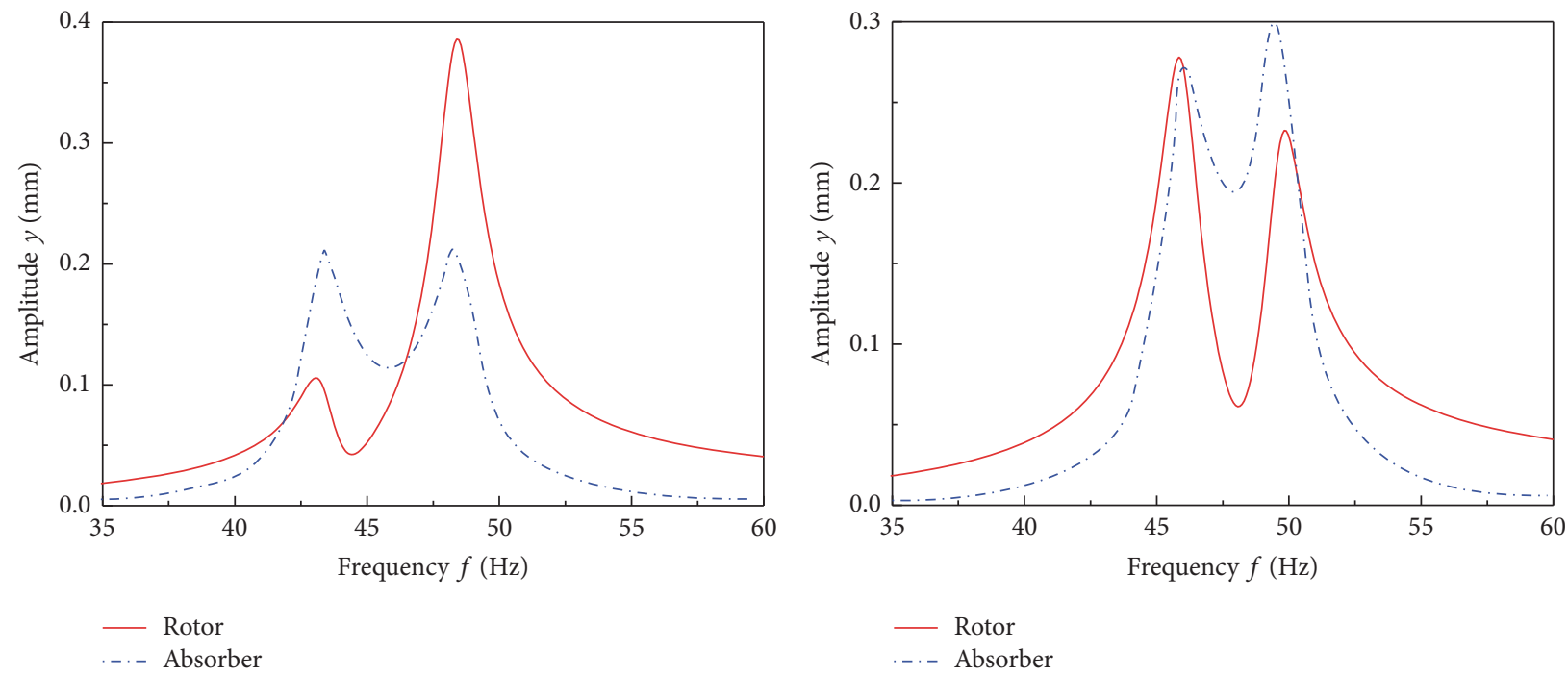

(a) $k_{3}=6 \times 10^{4} \mathrm{~N} / \mathrm{mm}$

(b) $k_{3}=7 \times 10^{4} \mathrm{~N} / \mathrm{mm}$

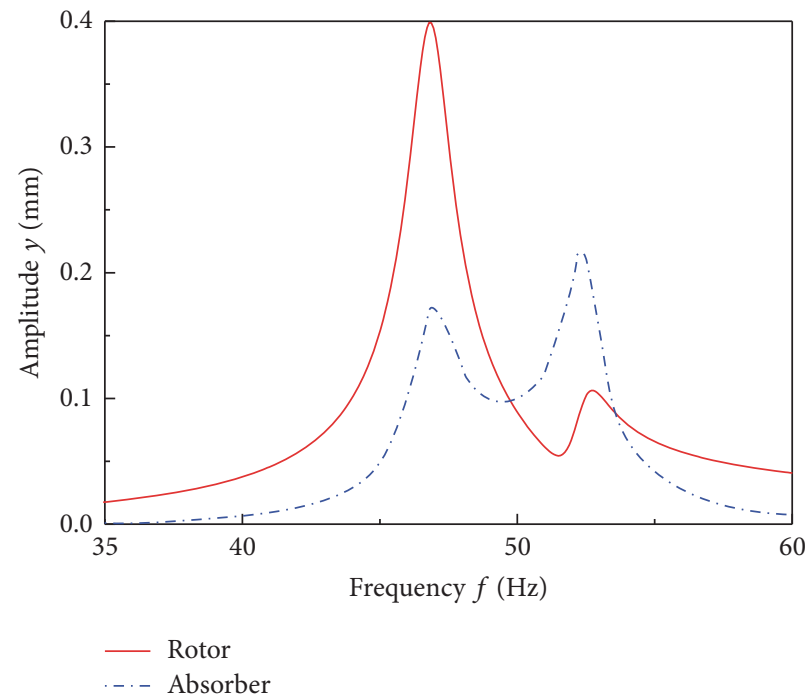

(c) $k_{3}=8 \times 10^{4} \mathrm{~N} / \mathrm{mm}$

FIGURE 8: Responses of the rotor-absorber system when $h$ is $10 \mathrm{~mm}$. 


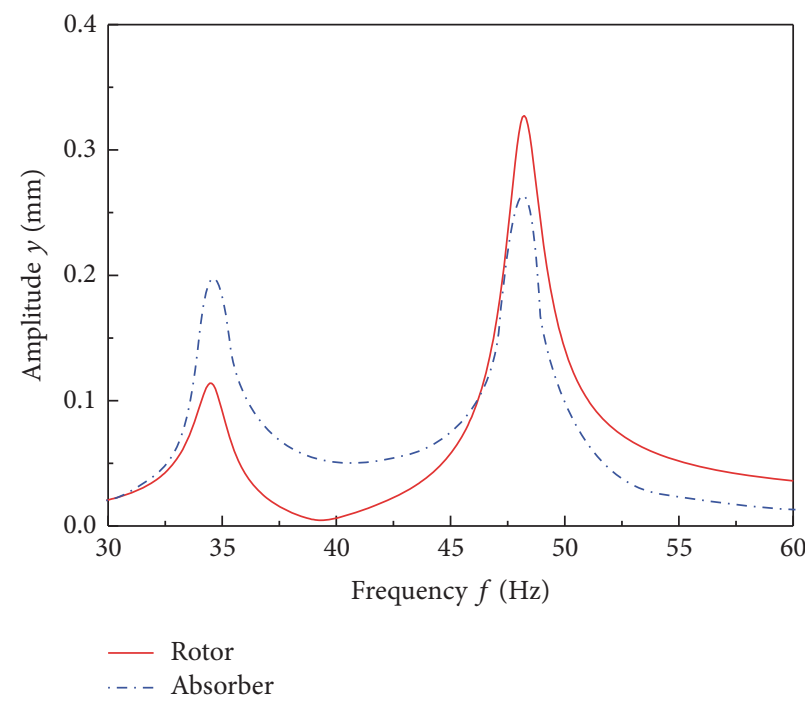

(a) $k_{3}=6 \times 10^{4} \mathrm{~N} / \mathrm{mm}$

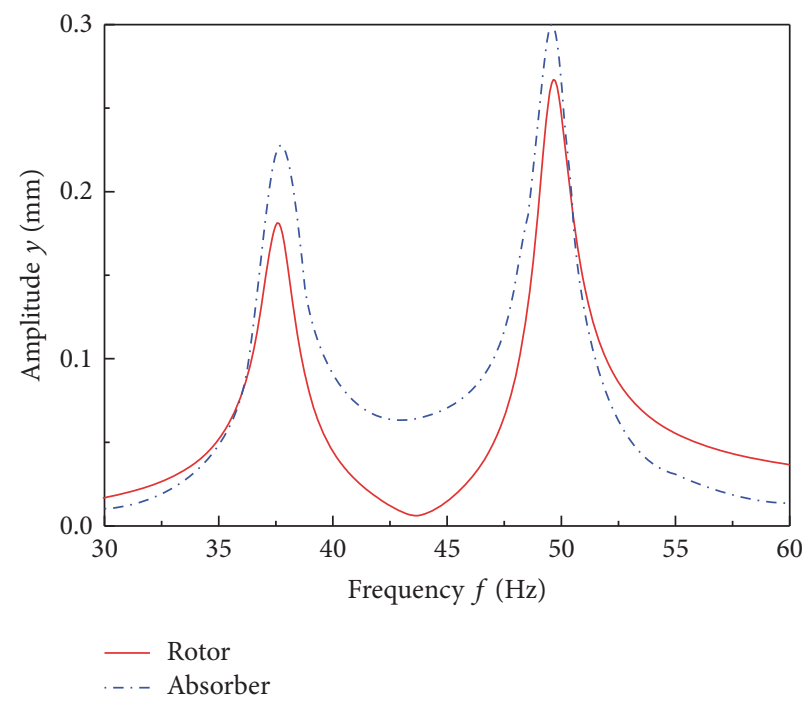

(b) $k_{3}=7 \times 10^{4} \mathrm{~N} / \mathrm{mm}$

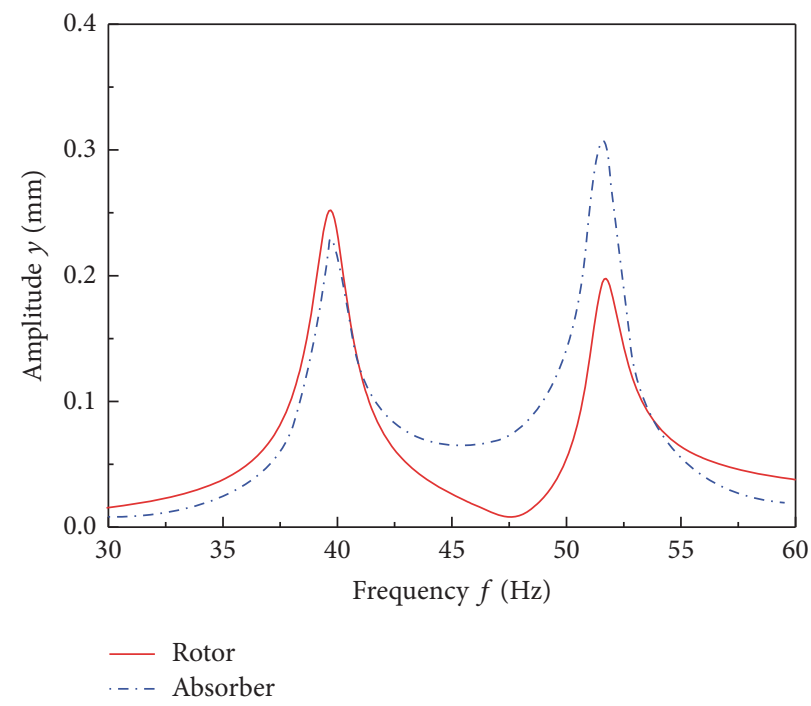

(c) $k_{3}=8 \times 10^{4} \mathrm{~N} / \mathrm{mm}$

FIGURE 9: Responses of the rotor-absorber system when $h$ is $5 \mathrm{~mm}$.

When the vibration is larger, strong nonlinearity phenomenon may appear in the resonance region, as shown in Figure 10, in which $k_{3}$ is $7 \times 10^{4} \mathrm{~N} / \mathrm{mm}$ and the eccentricity of the rotor is $\delta=0.1 \mathrm{~mm}$. But this case is very rare, as the vibration amplitude cannot be so great in real rotor systems in normal condition. Also, although the nonlinearity becomes stronger, the vibration suppression effects near antiresonant frequency remain the same.

\section{Experiments}

4.1. Experiment Setup. The experiments are carried out on the Bently Nevada test rig; the absorber is mounted on the single-disc rotor system, as shown in Figure 11. The lengths of the vertical and horizontal beam can be changed by changing the positions and heights of the manual tuning platforms. The parameters of the rotor system and the absorber are almost the same as those in Section 3. The vibration responses of the rotor are collected by eddy current transducer, and those of the absorber are collected by acceleration transducers. To prevent the rotation of the central magnet which is mounted on rolling bearings, a flexible copper wire is used, which holds the central magnet on one end and is fixed to the ground on the other end.

4.2. Experiment Results. To test the vibration suppression effect of the absorber, the vibration signals of the runup course are recorded and then the amplitude-frequency response curves of the rotor and the absorber are obtained. As the rotor system is symmetry in horizontal and vertical direction, only the responses of the vertical direction are studied.

Firstly, the amplitude-frequency response curve of the rotor system without absorber is obtained and shown in Figure 12. It can be seen that the natural frequency of the primary rotor system is about $50 \mathrm{~Hz}$. 


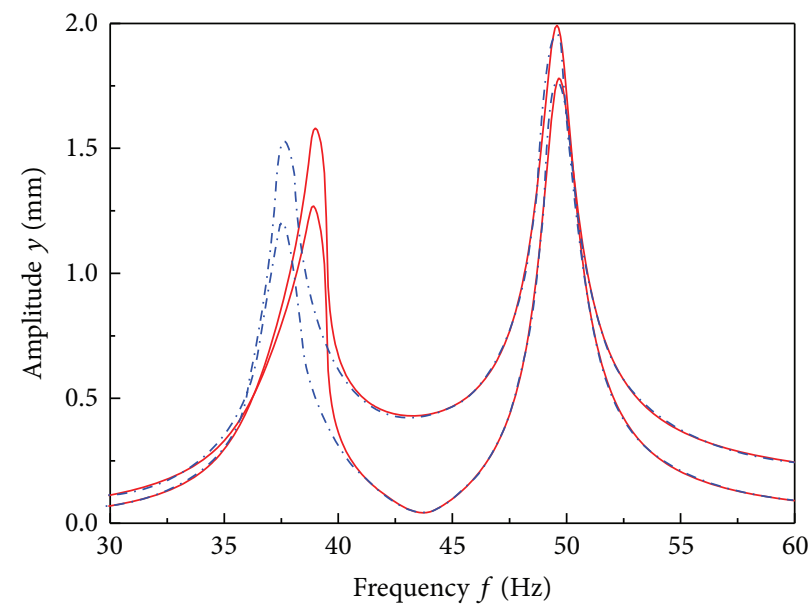

— With nonlinearity

-... Without nonlinearity

FIgURE 10: Responses of the rotor-absorber system when $h$ is $5 \mathrm{~mm}$ and $\delta$ is $0.1 \mathrm{~mm}$.

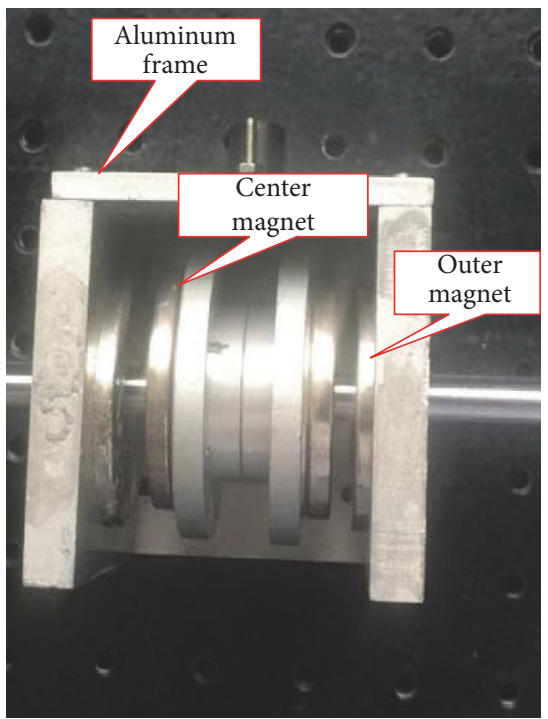

(a) Structure of the absorber

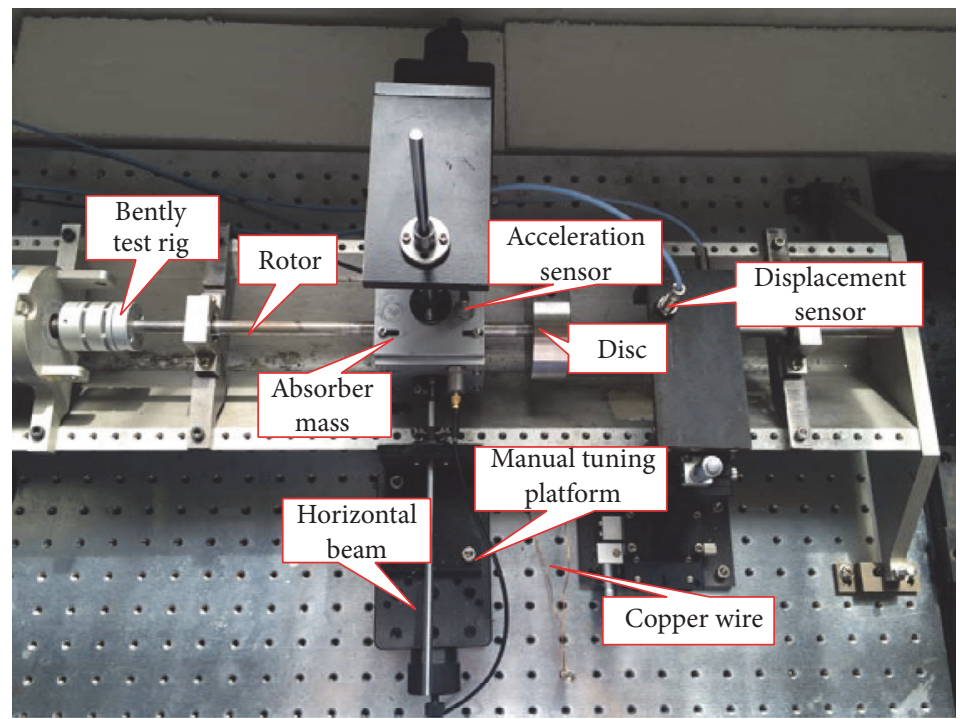

(b) Whole test rig

FIGURE 11: Experimental setup: the photo.

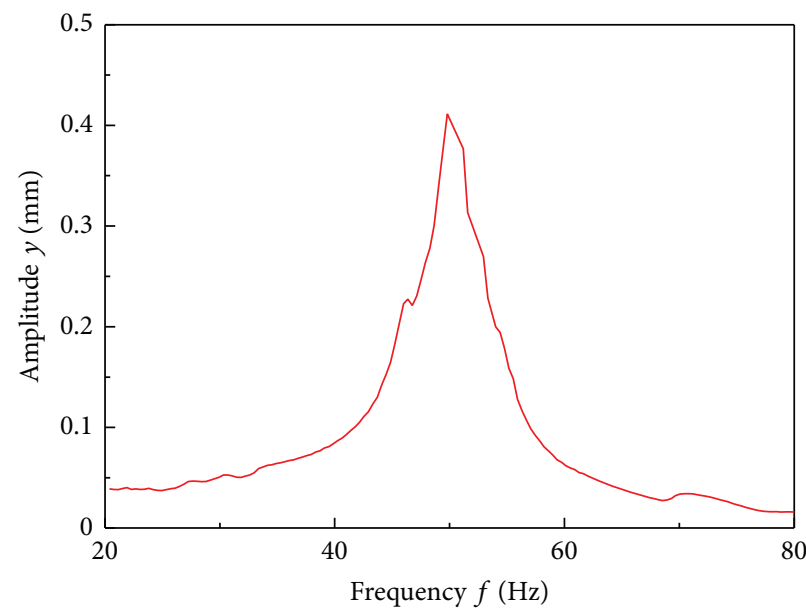

FIGURE 12: Response of the rotor system without the absorber. 


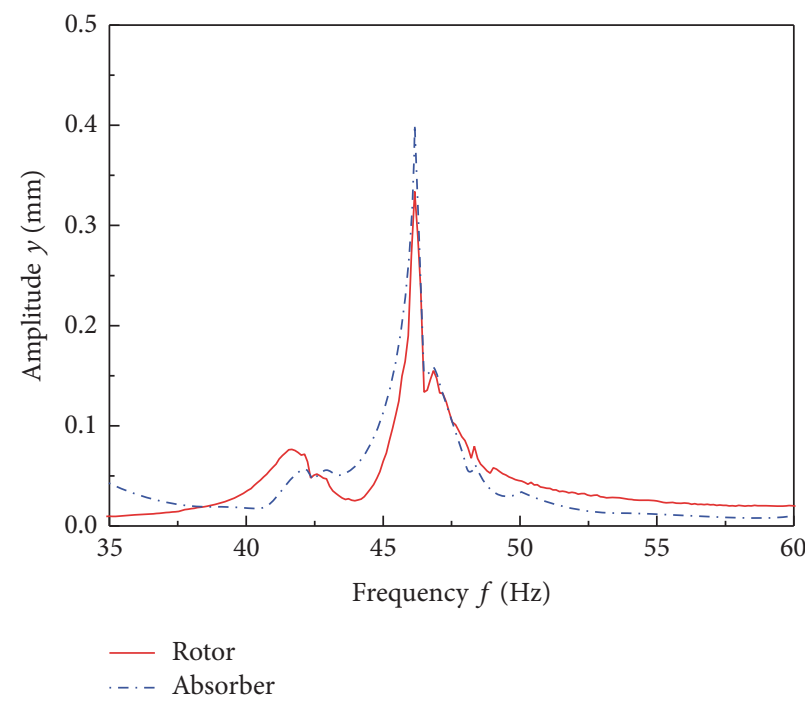

(a) $k_{3}=6 \times 10^{4} \mathrm{~N} / \mathrm{mm}$

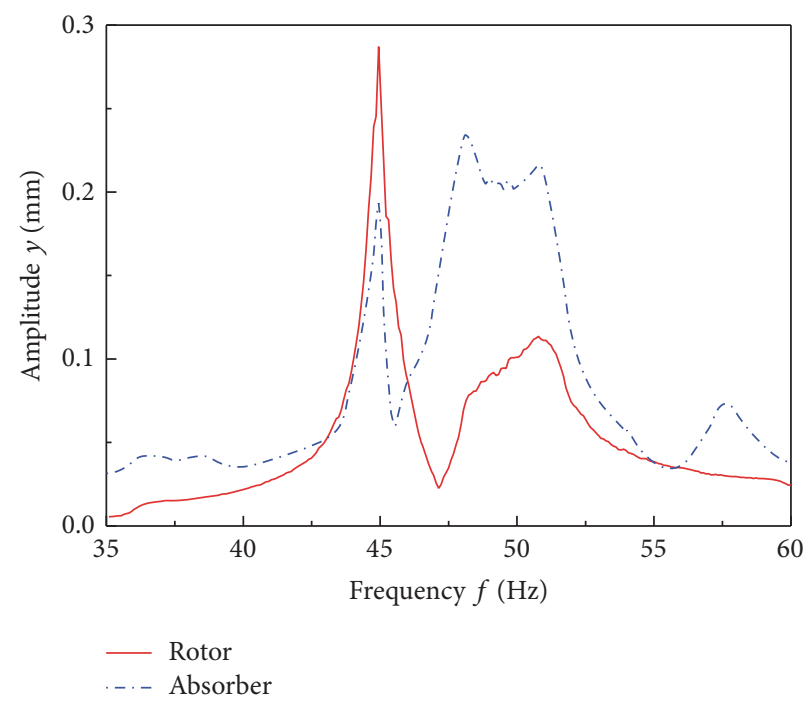

(b) $k_{3}=7 \times 10^{4} \mathrm{~N} / \mathrm{mm}$

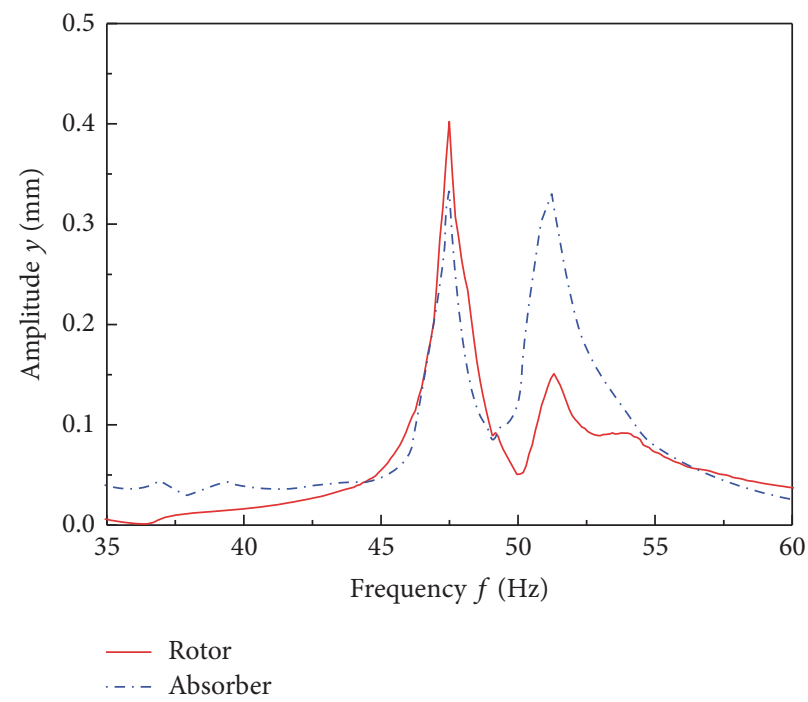

(c) $k_{3}=8 \times 10^{4} \mathrm{~N} / \mathrm{mm}$

FIGURE 13: Responses of the rotor-absorber system with different $k_{3}$ when $h$ is $10 \mathrm{~mm}$.

Then, the absorber is mounted on the rotor system and the amplitude-frequency response curves of rotor system and the absorber are obtained. The length $l$ of the absorber beams can be adjusted. Figures 13(a)-13(c) present the experiment results of the rotor and absorber responses when $h$ is $10 \mathrm{~mm}$ and $k_{3}$ is about $6 \times 10^{4} \mathrm{~N} / \mathrm{mm}, 7 \times 10^{4} \mathrm{~N} / \mathrm{mm}$, and $8 \times$ $10^{4} \mathrm{~N} / \mathrm{mm}$, respectively. Figures $14(\mathrm{a})-14$ (c) are corresponding results when $h$ is $5 \mathrm{~mm}$.

Comparing the experimental results with the numerical simulation results, it can be seen that there are still some differences between the experimental and the simulation results. There are additional resonance peaks in experimental results that are not present in the simulation results. The possible reason is that the additional resonance peaks are caused by rotational degree of freedom of the absorber. In the numerical simulations, the absorber is only modeled to move in $x$ and $y$ directions constrained by the beams, but the possibility of angular oscillations is not included. So the affections to the movement by the rotational degree of freedom are neglected.

But the main principles of the absorber can be verified after comparing the experimental results with the numerical simulation results:

(1) The vibration suppression effect can be verified by the experimental results. In all the cases, the vibration amplitudes near the antiresonant frequency are very low. Also, the antiresonant frequency of the rotor system moves to low frequency when the length of the beam increases, so the primary system can remain in low vibration state so far as the beam length is adjustable.

(2) The vibration suppression effect improves when the distance between the central magnet and the outer magnet reduced, which can be verified by comparing Figure 13 with Figure 14. 


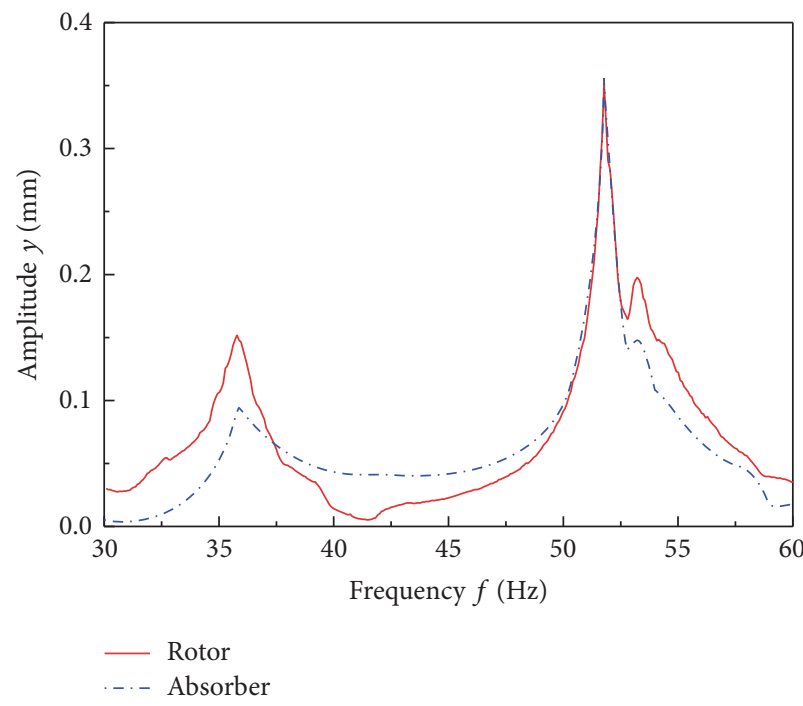

(a) $k_{3}=6 \times 10^{4} \mathrm{~N} / \mathrm{mm}$

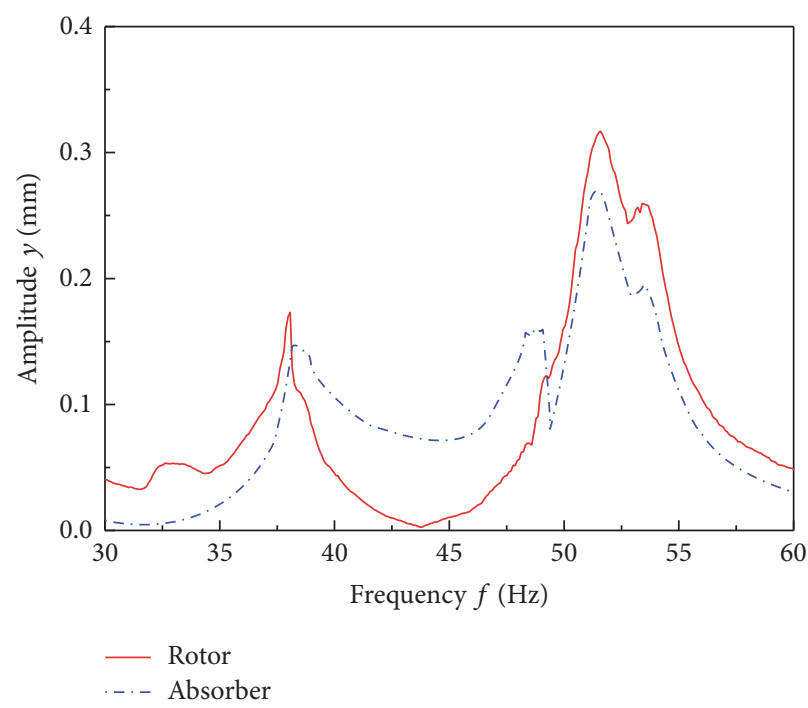

(b) $k_{3}=7 \times 10^{4} \mathrm{~N} / \mathrm{mm}$

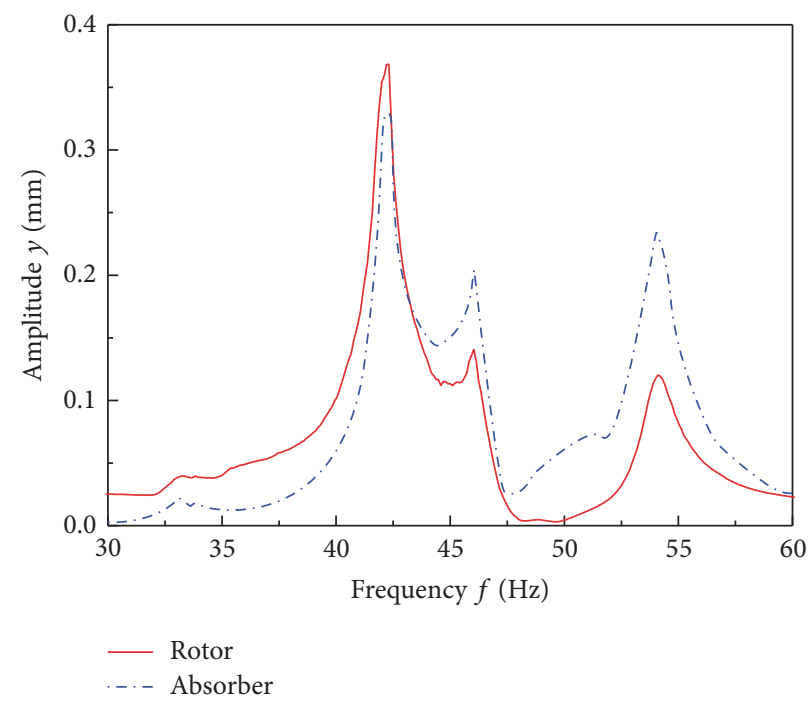

(c) $k_{3}=8 \times 10^{4} \mathrm{~N} / \mathrm{mm}$

FIGURE 14: Responses of the rotor-absorber system with different $k_{3}$ when $h$ is $5 \mathrm{~mm}$.

(3) The nonlinearity affects the suppression effect little, as the amplitude-frequency response curves show little "hard" or "soft" effect.

As the negative stiffness is adopted, the natural frequency of the absorber can be reduced, as it is determined by the combination of the negative stiffness and positive stiffness. This means that the negative stiffness can broaden the effective frequency range of the absorber. Also, as the adjustable stiffness connects to the ground, it will reduce the mass of the primary system, and it will be easy to add motor driven equipment and make it an automatic adjustable absorber.

\section{Conclusions}

A dynamic absorber combining negative stiffness with conventional positive stiffness for rotor system vibration suppression is proposed in this paper. The principles and fundamental characteristics of the absorber are studied analytically and experimentally and some conclusions are drawn as follows:

(1) The proposed dynamic absorber is effective, and the vibration suppression effect can be adjusted by changing the magnitude of negative stiffness and stiffness $k_{3}$. The antiresonant frequency increases with the increase of stiffness $k_{3}$; the vibration suppression effect improves when the magnitude of the negative stiffness is greater.

(2) The nonlinearity of the negative stiffness is weak and it affects the vibration suppression effect little in normal condition. 
(3) The absorber can keep efficiency at low frequency as the negative stiffness lowers the natural frequency of the absorber.

\section{Competing Interests}

The authors declare that there are no competing interests regarding the publication of this paper.

\section{Acknowledgments}

The authors would like to gratefully acknowledge the National Basic Research Program of China (2012CB026006) and the National Natural Science Foundation of China (Grant no. 51475085) for the financial support for this study.

\section{References}

[1] C. Chamroon, M. O. T. Cole, and T. Wongratanaphisan, "An active vibration control strategy to prevent nonlinearly coupled rotor-stator whirl responses in multimode rotor-dynamic systems," IEEE Transactions on Control Systems Technology, vol. 22, no. 3, pp. 1122-1129, 2014.

[2] K. Jiang and C. Zhu, "Multi-frequency periodic vibration suppressing in active magnetic bearing-rotor systems via response matching in frequency domain," Mechanical Systems and Signal Processing, vol. 25, no. 4, pp. 1417-1429, 2011.

[3] W. Wang, J. Gao, L. Huang, and Z. Xin, "Experimental investigation on vibration control of rotor-bearing system with active magnetic exciter," Chinese Journal of Mechanical Engineering, vol. 24, no. 6, pp. 1013-1021, 2011.

[4] S. E. Mushi, Z. Lin, and P. E. Allaire, "Design, construction, and modeling of a flexible rotor active magnetic bearing test rig," IEEE/ASME Transactions on Mechatronics, vol. 17, no. 6, pp. 1170-1182, 2012.

[5] Y. Ma, Q. Zhang, D. Zhang, F. Scarpa, B. Liu, and J. Hong, "A novel smart rotor support with shape memory alloy metal rubber for high temperatures and variable amplitude vibrations," Smart Materials and Structures, vol. 23, no. 12, Article ID 125016, 2014.

[6] Y. Ishida and J. Liu, "Vibration suppression of rotating machinery utilizing discontinuous spring characteristics (Stationary and nonstationary vibrations)," Journal of Vibration and Acoustics, vol. 130, no. 3, Article ID 031001, 2008.

[7] H. L. Zhou, G. H. Luo, G. Chen, and H. T. Tian, "Two dynamic models of dual clearance squeeze film damper and their verification," Tribology International, vol. 66, pp. 187-193, 2013.

[8] J. Laborenz, C. Siewert, L. Panning, J. Wallaschek, C. Gerber, and P.-A. Masserey, "Eddy current damping: a concept study for steam turbine blading," Journal of Engineering for Gas Turbines and Power, vol. 132, no. 5, Article ID 052505, 2010.

[9] M. Silvagni, A. Tonoli, and A. Bonfitto, "Self-powered eddy current damper for rotordynamic applications," Journal of Vibration and Acoustics, vol. 137, no. 1, Article ID 011015, 2015.

[10] M. Neubauer and J. Wallaschek, "Vibration damping with shunted piezoceramics: fundamentals and technical applications," Mechanical Systems and Signal Processing, vol. 36, no. 1, pp. 36-52, 2013.

[11] J. X. Wang and S. W. Wang, "Experiments on the vibration control of flexible rotor using shear mode MR elastomer damper," Applied Mechanics and Materials, vol. 215-216, pp. 741745, 2012.

[12] B. Dyniewicz, A. Pręgowska, and C. I. Bajer, "Adaptive control of a rotating system," Mechanical Systems and Signal Processing, vol. 43, no. 1-2, pp. 90-102, 2014.

[13] J. Zapoměl, P. Ferfecki, and P. Forte, "A computational investigation of the steady state vibrations of unbalanced flexibly supported rigid rotors damped by short magnetorheological squeeze film dampers," Journal of Vibration and Acoustics, vol. 135, no. 6, Article ID 064505, 2013.

[14] L. Mingfu, S. Mingbo, and W. Siji, "Active elastic support/dry friction damper with piezoelectric ceramic actuator," Shock and Vibration, vol. 2014, Article ID 712426, 10 pages, 2014.

[15] M. Rezaee and R. Fathi, "A new design for automatic ball balancer to improve its performance," Mechanism and Machine Theory, vol. 94, pp. 165-176, 2015.

[16] T. Kim and S. Na, "New automatic ball balancer design to reduce transient-response in rotor system," Mechanical Systems and Signal Processing, vol. 37, no. 1-2, pp. 265-275, 2013.

[17] C. Shi and R. G. Parker, "Vibration modes and natural frequency veering in three-dimensional, cyclically symmetric centrifugal pendulum vibration absorber systems," Journal of Vibration and Acoustics, vol. 136, no. 1, Article ID 011014, 2014.

[18] S. Bab, S. E. Khadem, and M. Shahgholi, "Vibration attenuation of a rotor supported by journal bearings with nonlinear suspensions under mass eccentricity force using nonlinear energy sink," Meccanica, vol. 50, no. 9, pp. 2441-2460, 2015.

[19] M. Jorkama and R. V. Hertzen, "Optimal dynamic absorber for a rotating Rayleigh beam," Journal of Sound and Vibration, vol. 217, no. 4, pp. 653-664, 1998.

[20] C. Guo, M. A. AL-Shudeifat, A. F. Vakakis, L. A. Bergman, D. M. McFarland, and J. Yan, "Vibration reduction in unbalanced hollow rotor systems with nonlinear energy sinks," Nonlinear Dynamics, vol. 79, no. 1, pp. 527-538, 2015.

[21] S. Bab, S. E. Khadem, and M. Shahgholi, "Lateral vibration attenuation of a rotor under mass eccentricity force using non-linear energy sink," International Journal of Non-Linear Mechanics, vol. 67, pp. 251-266, 2014.

[22] Y. Nakano, H. Takahara, and E. Kondo, "Countermeasure against chatter in end milling operations using multiple dynamic absorbers," Journal of Sound and Vibration, vol. 332, no. 6, pp. 1626-1638, 2013.

[23] F. J. Doubrawa Filho, M. A. Luersen, and C. A. Bavastri, "Optimal design of viscoelastic vibration absorbers for rotating systems," Journal of Vibration and Control, vol. 17, no. 5, pp. 699710, 2011.

[24] H. Moradi, F. Bakhtiari-Nejad, M. R. Movahhedy, and G. Vossoughi, "Stability improvement and regenerative chatter suppression in nonlinear milling process via tunable vibration absorber," Journal of Sound and Vibration, vol. 331, no. 21, pp. 4688-4690, 2012.

[25] R. O. Campos and R. Nicoletti, "Vibration reduction in vertical washing machine using a rotating dynamic absorber," Journal of the Brazilian Society of Mechanical Sciences and Engineering, vol. 37, no. 1, pp. 339-348, 2015.

[26] C. C. Cheng, F. T. Wu, K. S. Hsu, and K. L. Ho, "Design and analysis of auto-balancer of an optical disk drive using speeddependent vibration absorbers," Journal of Sound and Vibration, vol. 311, no. 1-2, pp. 200-211, 2008.

[27] W. Wu, X. Chen, and Y. Shan, "Analysis and experiment of a vibration isolator using a novel magnetic spring with negative 
stiffness," Journal of Sound and Vibration, vol. 333, no. 13, pp. 2958-2970, 2014.

[28] F. B. Sayyad and N. D. Gadhave, "Study of magnetic vibration absorber with permanent magnets along vibrating beam structure," Journal of Structures, vol. 2013, Article ID 658053, 5 pages, 2013.

[29] J. Sun, C. Wang, and Y. Le, "Research on a novel high stiffness axial passive magnetic bearing for DGMSCMG," Journal of Magnetism and Magnetic Materials, vol. 412, pp. 147-155, 2016.

[30] B. Han, S. Zheng, Y. Le, and S. Xu, "Modeling and analysis of coupling performance between passive magnetic bearing and hybrid magnetic radial bearing for magnetically suspended flywheel," IEEE Transactions on Magnetics, vol. 49, no. 10, pp. 5356-5370, 2013.

[31] J. X. Zhou and L. Zhang, "Incremental harmonic balance method for predicting amplitudes of a multi-d.o.f. non-linear wheel shimmy system with combined Coulomb and quadratic damping," Journal of Sound and Vibration, vol. 279, no. 1-2, pp. 403-416, 2005.

[32] J. V. Ferreira and A. L. Serpa, "Application of the arc-length method in nonlinear frequency response," Journal of Sound and Vibration, vol. 284, no. 1-2, pp. 133-149, 2005. 


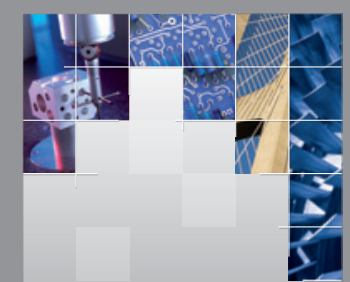

\section{Enfincering}
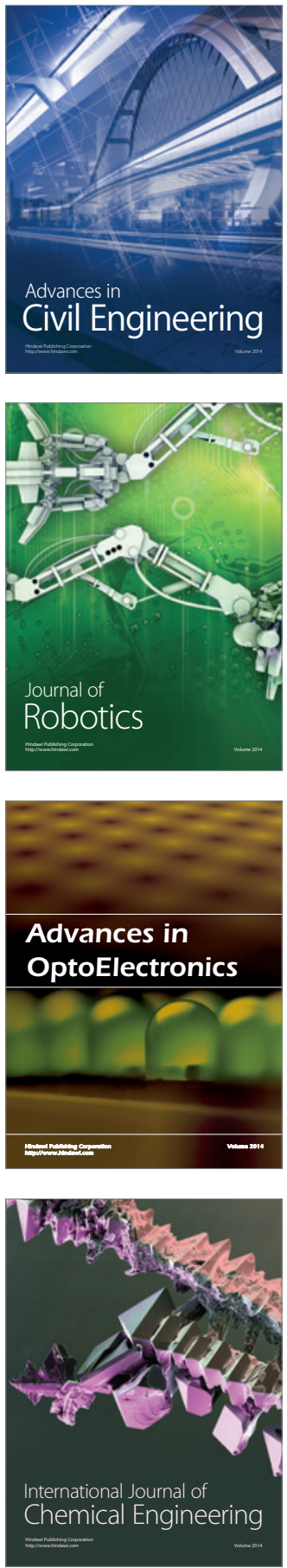

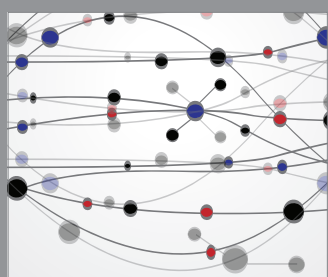

The Scientific World Journal

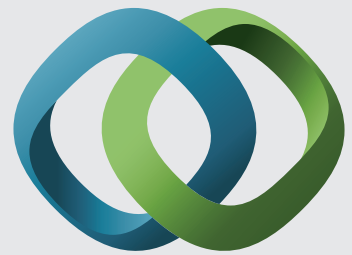

\section{Hindawi}

Submit your manuscripts at

http://www.hindawi.com
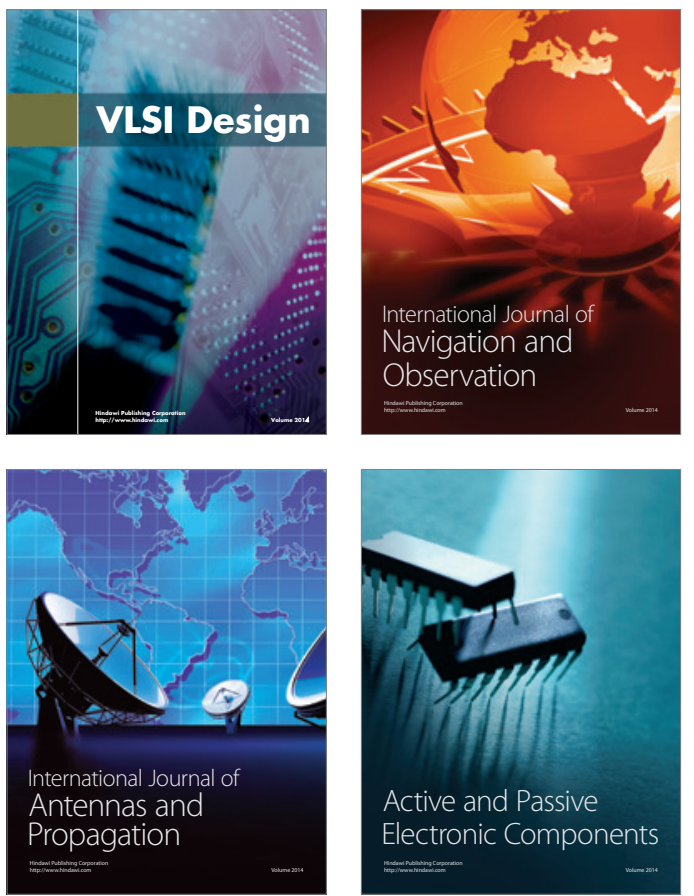
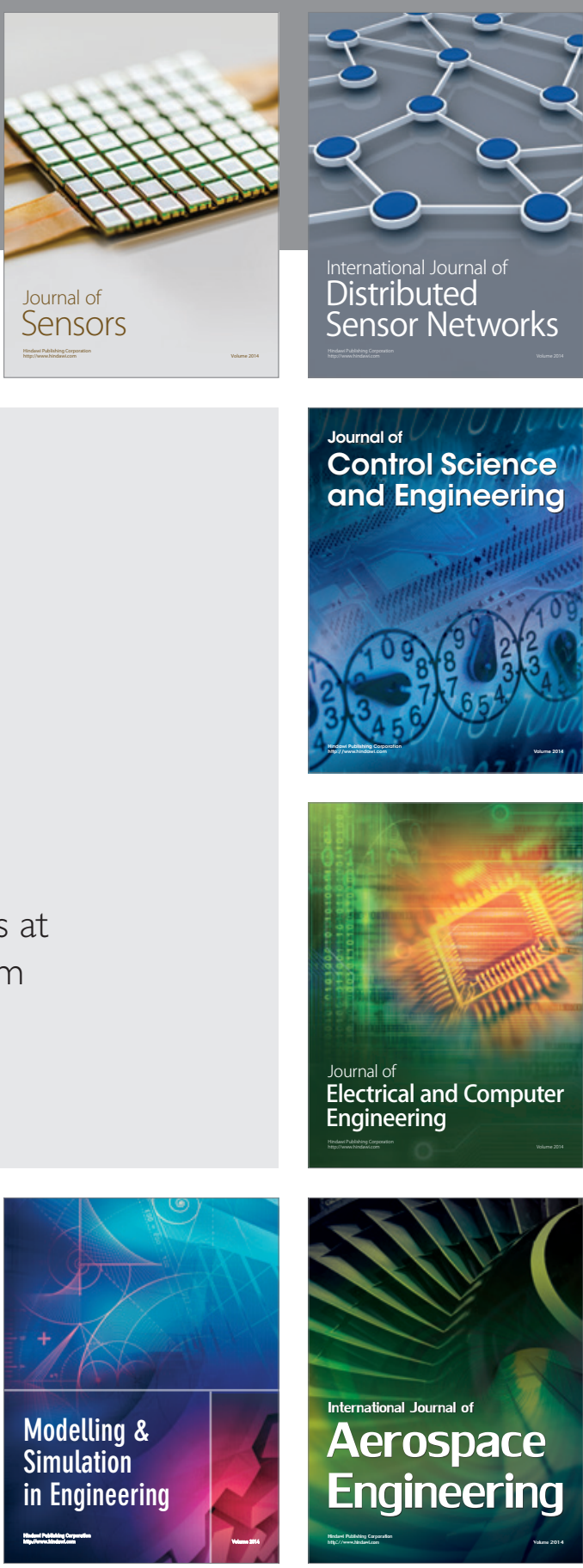

International Journal of

Distributed

Sensor Networks

Journal of

Control Science

and Engineering
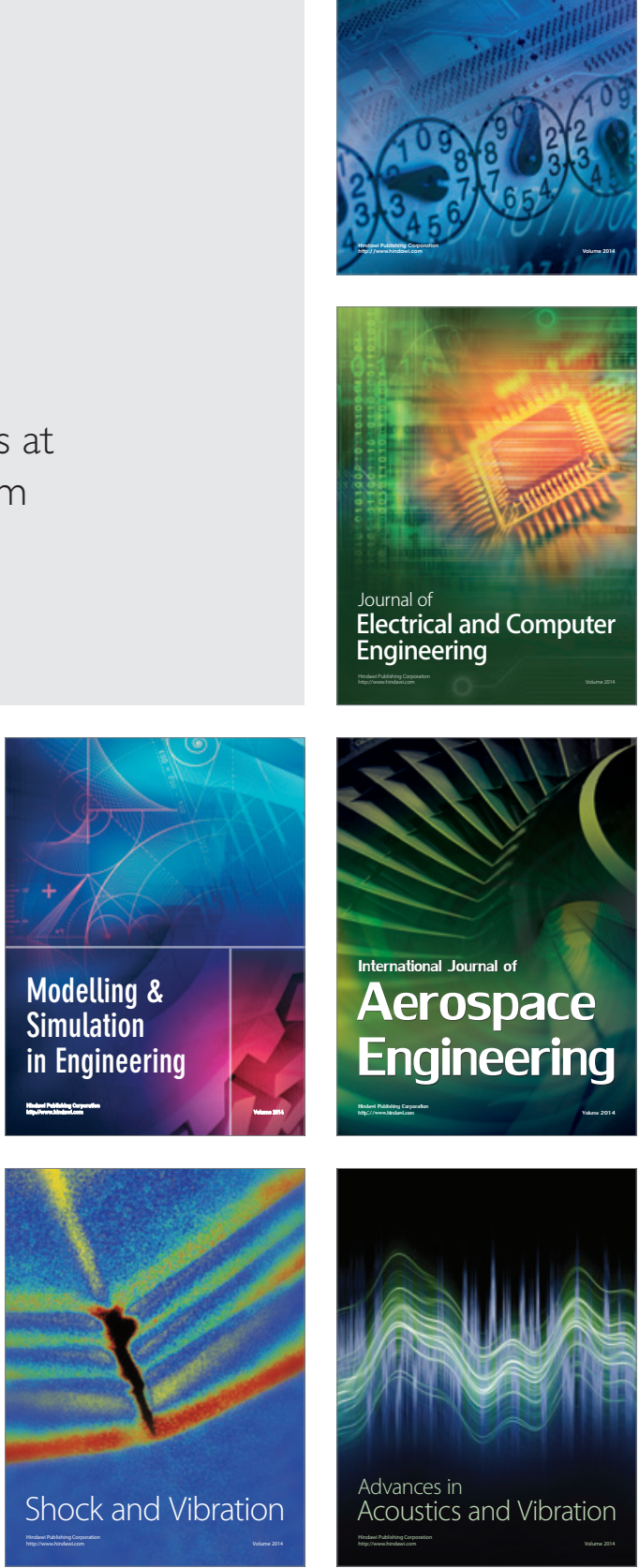